\title{
Fosfato e micorriza na estabilidade de agregados em amostras de latossolos cultivados e não-cultivados(1)
}

\author{
Júlio César Azevedo Nóbrega( ${ }^{(2)}$, José Maria de Lima(3), Nilton Curi(3), José Oswaldo Siqueira(3) \\ e Paulo Emilio Ferreira da Motta(4)
}

\begin{abstract}
Resumo - Nos trópicos, existe escassez de informação quanto à contribuição de espécies fúngicas do solo na formação e estabilização de agregados. Este estudo teve como objetivo avaliar o efeito do histórico de uso, níveis de $\mathrm{P}$, de inoculação micorrízica e cultivo com braquiária e soja em casa de vegetação, sobre o diâmetro médio geométrico dos agregados (DMG), o índice de floculação das partículas, a matéria seca das raízes, a colonização micorrízica e o comprimento total de hifas, em amostras de Latossolo Vermelho distrófico e Latossolo Vermelho distroférrico. Amostras dos dois solos, previamente cultivados por longos períodos, e de solos não-cultivados, foram trazidas para casa de vegetação, submetidas a inoculação, e a dois níveis de $\mathrm{P}$, e então cultivadas com braquiária e soja, em dois cultivos sucessivos. Os resultados mostraram que o solo previamente cultivado apresentou menor comprimento total de hifas, menor estabilidade de agregados (menor diâmetro médio de agregados) e menor índice de floculação. A inoculação propiciou maior estabilidade dos agregados, e este efeito é condicionado ao nível de $\mathrm{P}$ do solo e ao histórico de uso. A presença de $\mathrm{P}$ promoveu, indiretamente, maior agregação, por propiciar maior comprimento total das hifas e matéria seca de raízes.
\end{abstract}

Termos para indexação: braquiária, soja, adubação fosfatada, degradação do solo.

Aggregate stability in two cropped and no-cropped Oxisols as affected by phosphate addition and mycorrhiza

\begin{abstract}
In the tropics there is little information on the contribution of soil microorganisms on aggregate stability in the soils. Soil management, crop and fertilization can affect the fungi specie in soil, and also affect aggregate stability. This study attempted to evaluate the effect of earlier cropping, phosphate, inoculation with AMF, and brachiaria and soybean on the geometric mean diameter (GMD), particle flocculation index, root dry matter, and total hyphal length, in dystrophic Red Latosol and dystroferric Red Latosol (both Oxisols). Samples of both soils under natural condition and previously cultivated were brought to the green house and received $\mathrm{P}$ fertilization and inoculation. Then, they were cultivated twice with brachiaria and soybean. The results showed that the previously cultivated soils had lower total hyphal length and lower aggregate stability (lower GMD), whereas inoculation increased these parameters according to $P$ level. Phosphate fertilization had an indirect benefit on aggregate stability by increasing total hyphal length and root dry matter.
\end{abstract}

Index terms: brachiaria, soybeans, phosphate fertilizers, soil deterioration.

(1) Aceito para publicação em 11 de novembro de 2000. Extraído da Dissertação de Mestrado, apresentada pelo primeiro autor à Universidade Federal de Lavras (Ufla), Lavras, MG.

(2) Ufla, Dep. de Ciência do Solo, Caixa Postal 37, CEP 37200-000 Lavras, MG. Bolsista do CNPq. E-mail: jcesar@ufla.br

(3) Ufla, Dep. de Ciência do Solo. E-mail: jmlima@ufla.br, niltcuri@ufla.br,siqueira@ufla.br

(4) Embrapa-Centro Nacional de Pesquisa de Solos (CNPS), Rua Jardim Botânico, 1024, CEP 22460-000 Rio de Janeiro, RJ. E-mail: motta@enps.embrapa.br

\section{Introdução}

Os latossolos apresentam, no geral, características físicas bastante favoráveis à exploração agrícola. No entanto, quando submetidos ao uso agrícola intensivo, podem sofrer degradação da estrutura, causada pela maior dispersão dos colóides, translocação de argila no perfil do solo, aumento da densidade (Rosa Júnior, 1984), redução do tamanho dos agregados (Carpenedo \& Mielniczuk, 1990) e da macroporosidade (Rosa Júnior, 1984), com conse- 
qüente redução da taxa final de infiltração da água e do desenvolvimento do sistema radicular das plantas.

O uso de máquinas e implementos agrícolas (Carpenedo \& Mielniczuk, 1990), corretivos e fertilizantes (Rosa Júnior, 1984), tem sido apontado como responsável por essa degradação. A adsorção específica do $\mathrm{P}$ por grupos funcionais na superfície das partículas afeta o balanço de cargas no solo e pode causar dispersão e alterar a estabilidade dos agregados (Lima et al., 2000). A redução no tamanho de poros e a diminuição da resistência do solo à compactação podem também ser conseqüências da adsorção de fosfato (Silva et al., 1999). Por outro lado, o aumento da atividade microbiana do solo contribui para elevação da estabilidade dos agregados (Campos et al., 1995), fato que tem contribuído para aumentar o interesse no uso de microrganismos para melhorar a estrutura dos solos agrícolas. Além das bactérias produtoras de polissacarídeos (Dorioz et al., 1993), os microrganismos filamentosos, em especial os fungos, têm papel destacado na agregação (Tisdall \& Oades, 1982; Oades \& Waters, 1991; Andrade et al., 1998), e por isso podem contribuir para uma agricultura mais sustentável e para a restauração de ecossistemas. O efeito dos fungos na agregação se dá por três processos (Dorioz et al., 1993): 1) orientação de partículas de argila ao redor das células; 2) secreções de polissacarídeos, que induzem ligações locais de partículas de argilas, e, 3) efeito de "empacotamento" pelas hifas, que conduzem a uma nova microestrutura das partículas nas adjacências da célula. Tisdall (1994), em estudos realizados na Austrália, encontrou estreita relação entre o cultivo, o comprimento total das hifas e a proporção de agregados estáveis; ou seja, em solos cultivados ou em pousio foi observado menos de $5 \mathrm{~m}$ de hifas por $\mathrm{g}$ de solo e menos de $5 \%$ de agregados estáveis, enquanto no solo virgem esses valores chegaram a $17 \mathrm{~m}$ de hifas e $24 \%$ de agregados estáveis.

Se adição de fosfato pode promover a dispersão das partículas, os fungos micorrízicos arbusculares (FMAs) podem atenuar ou eliminar esse efeito dispersivo do $\mathrm{P}$ no solo, e preservar ou melhorar a agregação, através do aumento da capacidade de absorção de P pela planta, aumento de exsudatos no solo, e aumento no comprimento total das hifas e raízes finas, que propiciam maior emaranhamento dos microagregados em macroagregados.

O objetivo deste trabalho foi avaliar os efeitos da adubação fosfatada e de micorrizas na estabilidade de agregados, no índice de floculação de partículas, na quantidade de matéria seca de raiz, na colonização micorrízica e no comprimento total de hifas em Latossolo Vermelho distrófico e Latossolo Vermelho distroférrico não-cultivados, e cultivados por vários anos, e plantados com braquiária e soja em casa de vegetação.

\section{Material e Métodos}

Foram selecionados um Latossolo Vermelho distrófico (LVd) e Latossolo Vermelho distroférrico (LVdf), diferindo em teores de hematita, goethita, caulinita, gibbsita e condição inicial de fósforo. Ambos os solos foram coletados na camada de $0-20 \mathrm{~cm}$ (amostras compostas), sob condição de vegetação natural (cerrado tropical subcaducifólio e floresta tropical subcaducifólia, respectivamente) e sob cultivo por 10 e 15 anos, respectivamente. O LVd textura muito argilosa foi coletado no Município de Uberlândia, MG. Durante mais de 10 anos a área cultivada recebeu doses elevadas de adubos fosfatados e calagem, quando necessário. O LVdf textura argilosa foi coletado na região de Patos de Minas, MG; a área cultivada apresentou, por ocasião da coleta, mais de quinze anos de cultivo com lavouras anuais, principalmente milho, e mantida coberta com capim-braquiária (Brachiaria decumbens) durante cerca de cinco anos antes da amostragem.

Após a coleta, as amostras foram secadas ao ar, destorroadas, e passadas em peneira de $5 \mathrm{~mm}$ de malha. Subamostras desse material foram passadas em peneiras com malha de $2 \mathrm{~mm}$ e utilizadas nas caracterizações química, física e mineralógica. $\mathrm{O}$ complexo sortivo, $\mathrm{pH}$ em água, o $\mathrm{P}$ disponível, o $\mathrm{C}$ orgânico e os óxidos extraídos pelo ataque sulfúrico $\left(\mathrm{SiO}_{2}, \mathrm{Al}_{2} \mathrm{O}_{3}, \mathrm{Fe}_{2} \mathrm{O}_{3}, \mathrm{TiO}_{2}\right.$ e $\left.\mathrm{P}_{2} \mathrm{O}_{5}\right)$ foram determinados segundo Vettori (1969) e Embrapa (1997). A composição mineralógica da fração argila foi determinada por difração de raios-X (DRX), com lâminas orientadas. Após a concentração dos óxidos de ferro na fração argila, o material resultante foi, também, submetido à difração de raios-X, para a identificação e caracterização dos óxidos de ferro (Kämpf \& Schwertmann, 1982). A quantificação de caulinita e gibbsita foi feita por análise térmica diferencial no resíduo do tratamento com ditionitocitrato-bicarbonato (Mehra \& Jackson, 1960), após secagem em estufa e destorroamento suave em gral de ágata. Na Tabela 1 são apresentados os resultados da caracterização química e mineralógica dos solos estudados 
Antes da aplicação dos tratamentos, em cada solo fol fornecido calcário na quantidade indicada para elevar o valor da saturação por bases a $60 \%$, utilizando-se, calcário dolomítico com relação $\mathrm{Ca}: \mathrm{Mg}$ de aproximadamente 4:1 e PRNT próximo de $100 \%$. Após a calagem, foi feita uma adubação básica. As doses de $\mathrm{P}$ constituíram os tratamentos. Metade das amostras recebeu fosfato a $5 \%$ da dose necessária para a produção máxima, e a outra metade recebeu $50 \%$ da dose requerida para aquela produção; essas doses foram definidas com base em ensaio preliminar em casa de vegetação. As quantidades mínima (P0) e máxima (P1) aplicadas de P no LVd e LVdf foram, respectivamente, de 20 e 200, e 30 e $300 \mathrm{mg} \mathrm{kg}^{-1}$ de P. Nos vasos destinados ao cultivo da braquiária, foi também aplicado N, equivalente a $80 \mathrm{mg} \mathrm{kg}^{-1}$. Além da adubação básica, na qual o $\mathrm{K}$ e o $\mathrm{S}$ foram fornecidos nas concentrações de 80 e $35 \mathrm{mg} \mathrm{kg}^{-1}$, respectivamente, todos os vasos receberam micronutrientes de maneira a se atingirem as seguintes concentrações no solo em mg kg-1. $\mathrm{B}, 0,8 ; \mathrm{Fe}, 3,0 ; \mathrm{Cu}, 1,5 ; \mathrm{Mn}, 3,6 ; \mathrm{Zn}, 5,0$, e Mo, 0,15 ; as adubações básica e de micronutrientes foram feitas após a calagem. Com exceção do calcário dolomítico e do $\mathrm{CaSO}_{4} \cdot 2 \mathrm{H}_{2} \mathrm{O}$, fornecidos nas formas de pó, os demais nutrientes foram aplicados na forma de solução nutritiva, e misturados aos solos, para melhor uniformização. Posteriormente, os solos foram incubados por um período de 45 dias, mantendo-se a umidade em torno de $60 \%$ do volume total de poros. Após o período de incubação, os solos foram fumigados com brometo de metila. Decorrido o período necessário para ventilação do material, foi feita a inoculação nos tratamentos que incluíam o Glomus etunicatum, adicionando-se $1 \mathrm{~mL}$ da suspensão de esporos, obtida pelo método de Gerdermann \& Nicolson (1963), sendo o volume e concentração ajustados para aplicação de 300 esporos por vaso.
Os tratamentos, correspondendo a duas condições de uso anterior do solo (cultivado e não-cultivado), duas de doses de $\mathrm{P}$ (P0 e P1) e duas condições biológicas (presença e ausência de Glomus etunicatum), foram dispostos num delineamento inteiramente casualizado, em esquema fatorial 2 × 2 × 2 na braquiária e soja, em quatro repetições, totalizando 128 vasos

Foram realizados dois cultivos sucessivos com braquiária (Brachiaria decumbens) e soja (Glycine max), variedade CAC-1, em vasos com capacidade para $4 \mathrm{~kg}$ de solo. Quanto à braquiária, foram utilizadas cerca de dez sementes por vaso, e para a soja, quatro sementes; foram mantidas duas plantas por vaso, após o desbaste. Antes do plantio, as sementes de soja foram infectadas com Bradyrhizobium japonicum, procedente da Embrapa-Centro Nacional de Pesquisa de Agrobiologia. Após o plantio, foi feita a recomposição parcial da microbiota do solo, via aplicação de filtrado, obtido a partir do próprio solo sem fumigação. Durante o cultivo, a umidade foi mantida na capacidade de campo. Ao final do segundo cultivo, as plantas foram cortadas rente ao solo, e as raízes foram lavadas e amostradas, para avaliação da colonização micorrízica pelo método de interseção em placas reticuladas (Giovannetti \& Mosse, 1980), e então, levadas para estufa e aí deixadas por 72 horas, a $60^{\circ} \mathrm{C}$, com circulação de ar forçada, para determinação da produção de matéria seca (MSR).

O solo contido em cada vaso foi secado ao ar, e em seguida, passado em peneiras de malhas de 4,76 e 2,00 mm. Os agregados na faixa de 4,76 e 2,00 $\mathrm{mm}$ foram utilizados para determinação da estabilidade dos agregados, em cada tratamento, por peneiramento úmido, segundo Kemper \& Rosenau (1986), e comprimento total das hifas, por massa de agregado, segundo Melloni \& Cardoso (1999). De acordo

Tabela 1. Características químicas e mineralógica do Latossolo Vermelho distrófico (LVd) e Latossolo Vermelho distroférrico (LVdf) ${ }^{(1)}$.

\begin{tabular}{|c|c|c|c|c|c|c|c|c|c|c|c|c|c|}
\hline $\mathrm{pH}$ & \multicolumn{2}{|c|}{----- $\left(\mathrm{cmol}_{\mathrm{c}} \mathrm{dm}^{-3}\right)$----- } & $\begin{array}{l}\mathrm{Mg}^{2+} \\
3 \\
\end{array}$ & \multicolumn{2}{|c|}{$\left(\mathrm{mg} \mathrm{dm}^{-3}\right)$} & \multicolumn{3}{|c|}{--- $\left(\mathrm{cmol}_{\mathrm{c}} \mathrm{dm}^{-3}\right)$--- } & \multicolumn{2}{|c|}{---- $(\%)$---- } & \multicolumn{3}{|c|}{------ $\left(\mathrm{g} \mathrm{kg}^{-1}\right)$----- } \\
\hline & & & & & & $\mathrm{LVC}$ & $\mathrm{O}-\mathrm{cul}$ & rado & & & & & \\
\hline \multirow[t]{2}{*}{4,9} & 0,9 & 1,2 & 0,1 & 36 & 7 & 1,4 & 2,3 & 11,2 & 13 & 39 & 26,4 & 230 & 270 \\
\hline & \multicolumn{13}{|c|}{ LVd cultivado } \\
\hline \multirow[t]{2}{*}{5,8} & 0,0 & 3,7 & 0,2 & 59 & 48 & 4,1 & 4,1 & 7,0 & 58 & 0 & 19,1 & 190 & 110 \\
\hline & \multicolumn{13}{|c|}{ LVdf não-cultivado } \\
\hline \multirow[t]{2}{*}{4,9} & 0,8 & 2,3 & 0,9 & 64 & 91 & 3,4 & 4,2 & 15,7 & 21 & 19 & 49,5 & 0 & 260 \\
\hline & \multicolumn{13}{|c|}{ LVdf cultivado } \\
\hline 5,2 & 0,2 & 2,2 & 1,1 & 166 & 57 & 3,7 & 3,9 & 10,7 & 35 & 5 & 31,9 & 0 & 300 \\
\hline
\end{tabular}


com a metodologia, a extração do micélio extrarradicular foi feita com os seguintes procedimentos: 1) pesagem de $10 \mathrm{~g}$ de agregados, paralelamente à pesagem de uma subamostra para determinação do teor de umidade; 2) preparo de suspensão misturando os agregados, previamente destorroados em gral de ágata, com $1.500 \mathrm{~mL}$ de água de torneira; 3 ) peneiramento em malhas de 0,71 e $0,25 \mathrm{~mm}$; 4) agitação em liquidificador por 30 segundos na menor velocidade; 5) repouso da suspensão por 2 minutos; 6) retirada de alíquota de $500 \mathrm{~mL}$; 7) peneiramento em malha de $44 \mu \mathrm{m}$; e 8) transferência do retido na peneira com $11 \mathrm{~mL}$ de água destilada para frasco de $15 \mathrm{~mL}$ de capacidade. Para a quantificação das hifas totais, acoplou-se na ocular do microscópio uma ocular reticulada (área de 100 mm² contendo dez linhas verticais e dez horizontais, no aumento de dez vezes). A área correspondente ao reticulado era sobreposta a cada campo da membrana, num total de 64 campos. Em cada campo, avaliou-se o número de interseções de hifas com as linhas horizontais do reticulado, e aplicou-se a equação de Newman (1966), corrigindo o valor obtido de acordo com o teor de água presente no solo e os volumes das alíquotas utilizadas, ou seja:

$\mathrm{C}=0,21387 \mathrm{n} /(10-\mathrm{U})$,

onde: C é o comprimento de micélio extrarradicular, $\mathrm{em} \mathrm{g}^{-1}$ de solo seco; n é o número de interseções de hifas com as linhas horizontais do reticulado; U é a quantidade de água presente em dez gramas de agregado úmido, em gramas.

O material passado na peneira de $2,00 \mathrm{~mm}$ foi utilizado para determinação do índice de floculação de partículas, conforme Embrapa (1997).

\section{Resultados e Discussão}

Os resultados de diâmetro médio geométrico (DMG) (Figura 1), índice de floculação de partículas (IF) (Figura 2), produção de matéria seca das raízes (MSR) (Figura 3) e comprimento total de hifas (CTH) (Figura 4) estão distribuídos de forma a verificar, nas interações duplas, os seguintes efeitos: doses de $\mathrm{P}$ dentro de cada histórico de uso; inoculação dentro de cada histórico de uso; e inoculação dentro de cada dose de fósforo. Embora observado efeito de interação tripla das variáveis DMG e CTH no LVd com braquiária e CTH no LVdf com braquiária e soja, estas não são discutidas neste trabalho.

No LVd com braquiária, a interação $(\mathrm{P}<0,05)$ entre o histórico de uso e a inoculação com Glomus etunicatum (Figura 1e), mostra maior DMG no solo não-cultivado, e submetido a inoculação. Efeito de fungos micorrízicos na agregação foram também verificados por Tisdall \& Oades (1982), Oades \& Waters (1991) e Andrade et al. (1998). Quanto à soja, verificou-se interação $(\mathrm{P}<0,05)$ entre o histórico de uso e a adubação fosfatada (Figura 1b). Neste caso, a maior dose de P aumentou, indiretamente, o DMG no solo cultivado, provavelmente devido à maior produção de MSR ou ao crescimento das hifas dos fungos micorrízicos nesta dose. No LVd, foi observado que, independentemente da cultura, o solo não-cultivado apresenta maior DMG que o solo cultivado (Figura 1 $(\mathrm{a}, \mathrm{b}, \mathrm{e}, \mathrm{f})$ ). Maiores teores de $\mathrm{C}$ (Tisdall \& Oades, 1982) e gibbsita (Ferreira et al., 1999), conforme verificados na Tabela 1, e a inexistência de práticas de cultivo são, entre outros fatores, os responsáveis por essa tendência.

No LVdf com braquiária é verificada interação $(\mathrm{P}<0,01)$ entre o histórico de uso e adubação fosfatada (Figura 1c). O solo cultivado, na maior dose de $\mathrm{P}$, apresentou menor DMG. Embora esse comportamento possa indicar um possível efeito dispersivo do P sobre o DMG (Silva et al., 1999), tal fato parece estar relacionado a uma falta de ação do Glomus etunicatum nesse tratamento, já que as raízes não foram colonizadas pelo fungo (Tabela 2). Na menor dose de $\mathrm{P}$, em que as raízes foram colonizadas, o DMG aumentou, possivelmente devido à maior quantidade das hifas do Glomus etunicatum. No solo com braquiária, interação $(\mathrm{P}<0,05)$ é também verificada entre o histórico de uso e inoculação (Figura 1g). A inoculação no solo não-cultivado aumentou o DMG. No LVdf com soja, é observada interação $(P<0,05)$ entre a adubação fosfatada e a inoculação (Figura 11), comportamento semelhante ao observado no LVd com soja, em que inoculação na maior dose de P aumentou o DMG. No LVdf com soja é verificado, ao contrário do observado com braquiária, efeito individual do histórico de uso sobre o DMG (Figura $1(\mathrm{~d}, \mathrm{~h})$ ), o que mostra maior eficiência da braquiária na formação ou estabilização dos agregados. Maior efeito de gramíneas na agregação do solo ocorre segundo Tisdall \& Oades (1979), Carpenedo \& Mielniczuk (1990) e Silva \& Mielniczuk (1997), devido à maior densidade das raízes, às periódicas renovações do sistema radicular, e à uniforme distribuição dos exsudatos no solo, que estimulam a atividade microbiana, promovendo maior agregação. 
Latossolo Vermelho distrófico

$$
\text { Braquiária }
$$

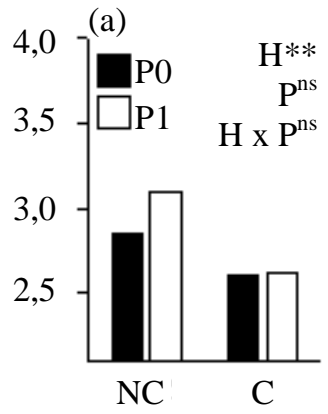

ఏ્ఏ

(e)

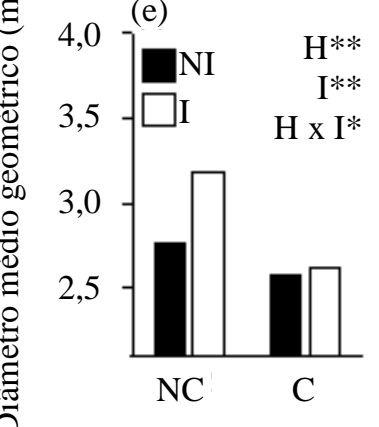

(i)

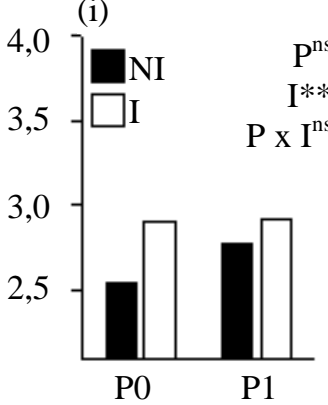

Soja

(b)

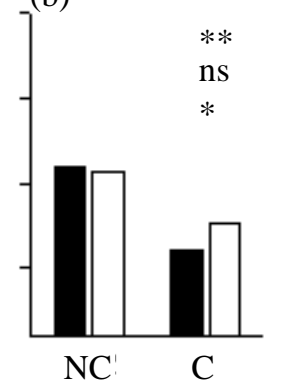

Latossolo Vermelho distroférrico

Braquiária

Soja

(c)

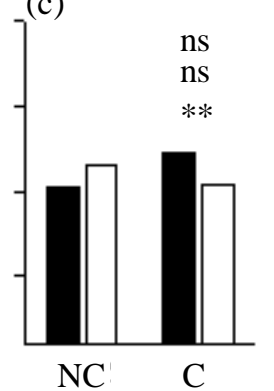

(d)

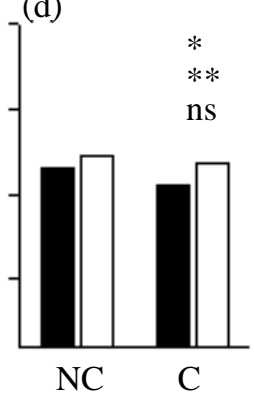

Histórico de uso

(f)

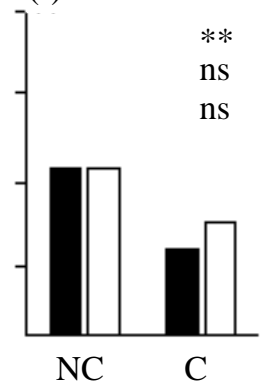

(g)
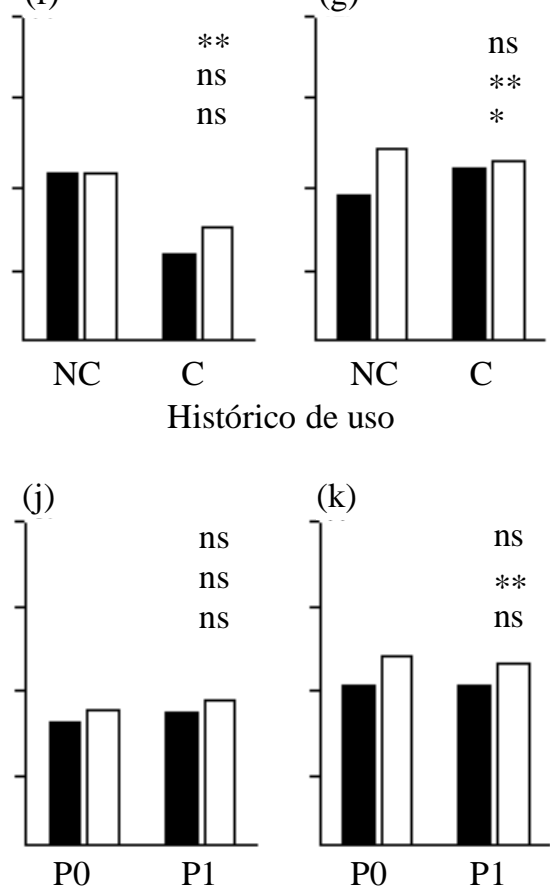

(k)

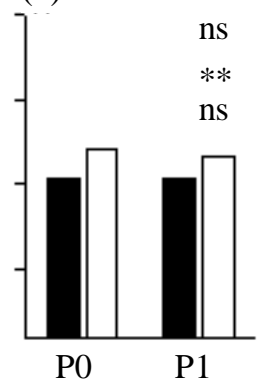

(h)

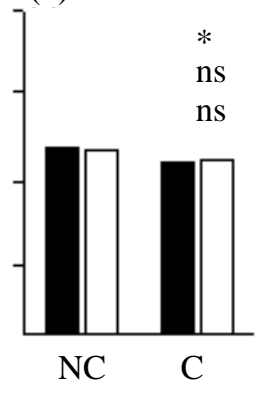

(1)

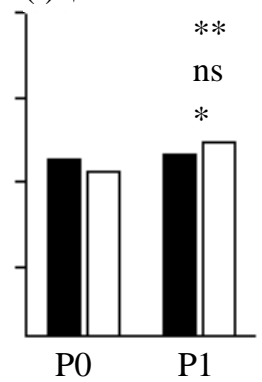

Níveis de fósforo

Figura 1. Efeito do histórico de uso, adubação fosfatada e inoculação, sobre a estabilidade dos agregados (diâmetro $>2 \mathrm{~mm}$ ) de Latossolo Vermelho distrófico e Latossolo Vermelho distroférrico plantados com braquiária e soja ( $\mathrm{P}$ : doses de fósforo; $\mathrm{H}$ : histórico de uso ( $\mathrm{NC}$ : não-cultivado e $\mathrm{C}$ : cultivado); NI: não-inoculado; I: inoculado). ns Não-significativo. * e **Significativo a $5 \%$ e a $1 \%$ de probabilidade, respectivamente. 
Latossolo Vermelho distrófico

Braquiária

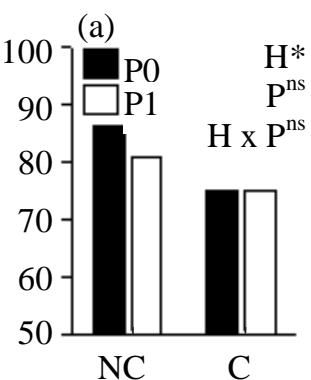

(e)
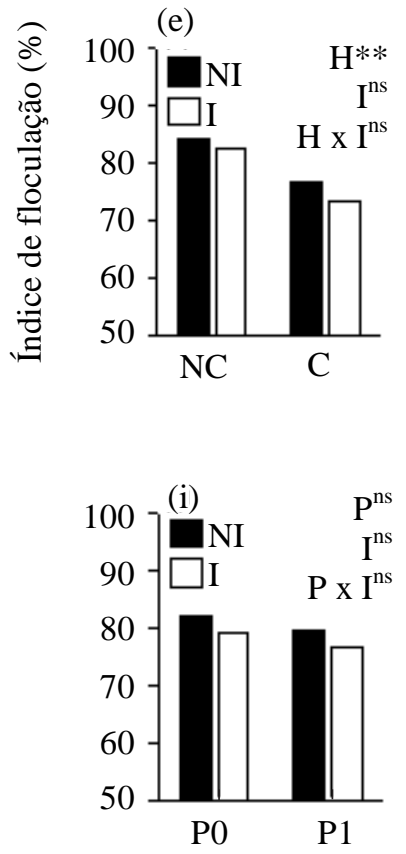

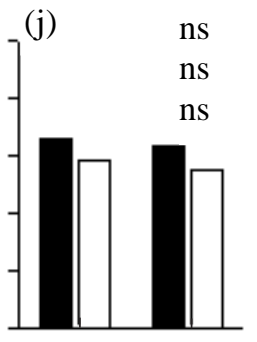

P0

Latossolo Vermelho distroférrico

Soja

(b)

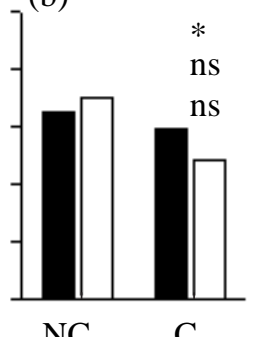

Braquiária

(c)

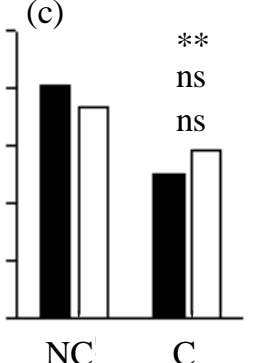

NC $\mathrm{C}$

(f)

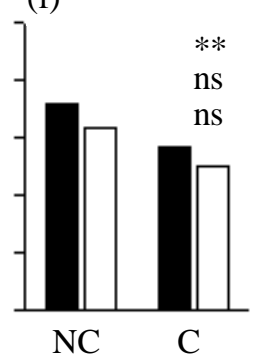

(g)

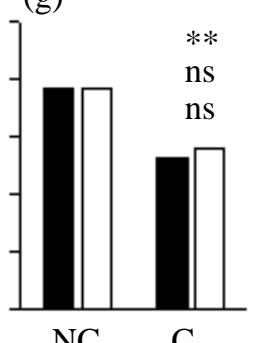

(h)

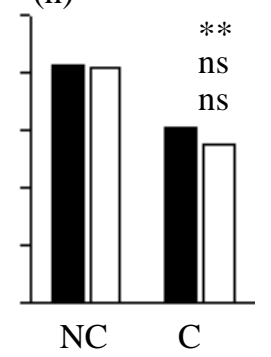

$\mathrm{NC} \quad \mathrm{C}$

Histórico de uso

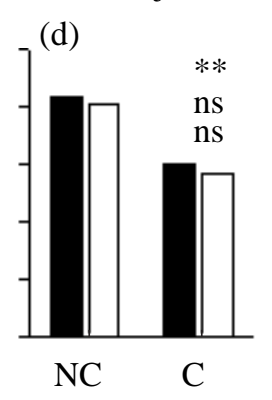
Soja
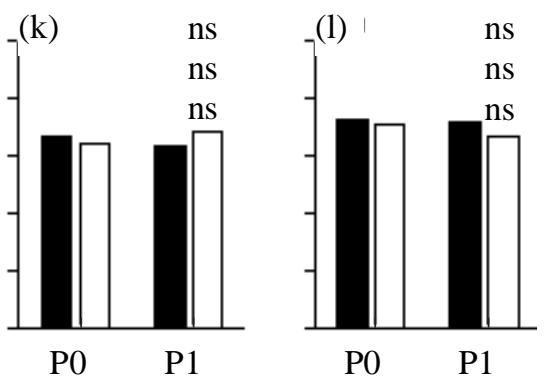

P0 P1

Níveis de fósforo

Figura 2. Efeito do histórico de uso, adubação fosfatada e inoculação, sobre o índice de floculação das argilas em Latossolo Vermelho distrófico e Latossolo Vermelho distroférrico plantados com braquiária e soja (P: doses de fósforo; H: histórico de uso (NC: não-cultivado e C: cultivado); NI: não-inoculado; I: inoculado). ${ }^{n} \mathrm{Não}$-significativo. $* \mathrm{e}^{* *}$ Significativo a $5 \%$ e a $1 \%$ de probabilidade, respectivamente.

No LVd (Figura 2 (a, b, e, f)) e LVdf (Figura 2 (c, d, g, h)), com braquiária e soja, houve efeito individual do histórico de uso sobre o IF. Efeitos de cultivo sobre dispersão de partículas foram também verificados por Rosa Júnior (1984), o qual associou, entre outros aspectos, às modificações promovidas pela calagem, e Buttierres (1980), que destacou, além da calagem, a fosfatagem nesse processo. Neste estudo não foi observado efeito do $\mathrm{P}$ sobre $\mathrm{o}$ IF em nenhum dos casos estudados, embora, no campo, 
Latossolo Vermelho distrófico

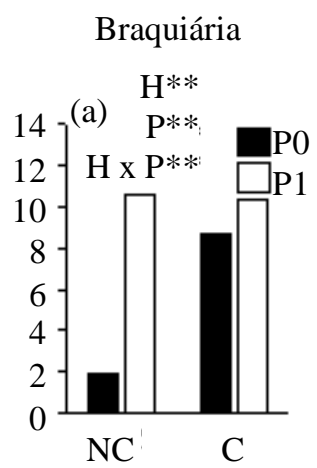

Soja

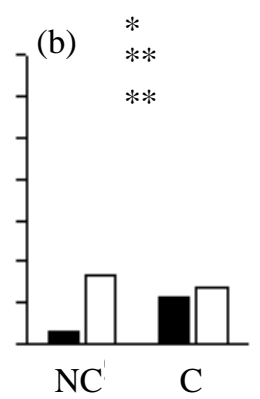

Latossolo Vermelho distroférrico

Braquiária

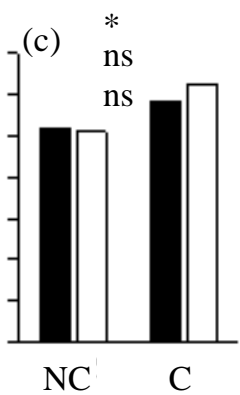

$\mathrm{C}$
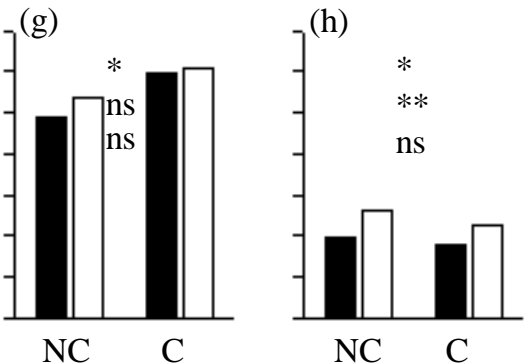

Histórico de uso
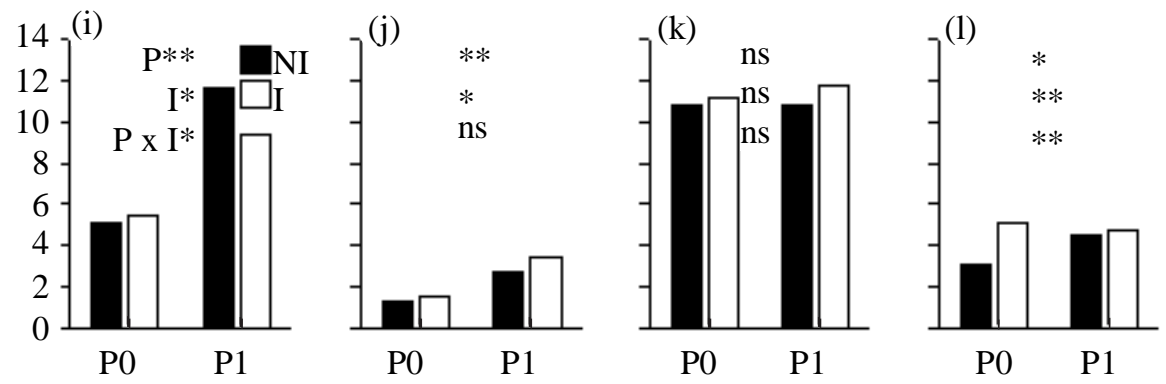

Níveis de fósforo

Figura 3. Efeito do histórico de uso, adubação fosfatada e inoculação sobre a produção de matéria seca de raiz de braquiária e soja plantado em um Latossolo Vermelho distrófico e Latossolo Vermelho distroférrico (P: doses de fósforo; H: histórico de uso (NC: não-cultivado e C: cultivado); NI: não-

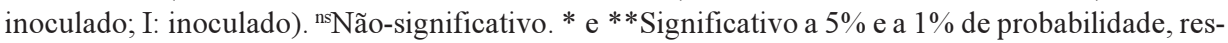
pectivamente.

durante o uso anterior do solo, esse nutriente possa ter contribuído para elevar a porcentagem de argila dispersa no solo cultivado. O menor IF no solo cultivado reflete-se também no menor DMG (Figura $1(\mathrm{a}, \mathrm{b}, \mathrm{e}, \mathrm{f})$ ).
No LVd com braquiária houve interação $(\mathrm{P}<0,01)$ entre o histórico de uso e adubação fosfatada (Figura 3a). No solo não-cultivado, há maior resposta à dose de $\mathrm{P}$ com maior produção de MSR, os quais 
Latossolo Vermelho distrófico

Braquiária

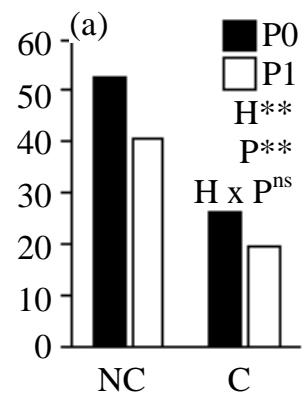

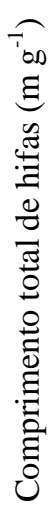
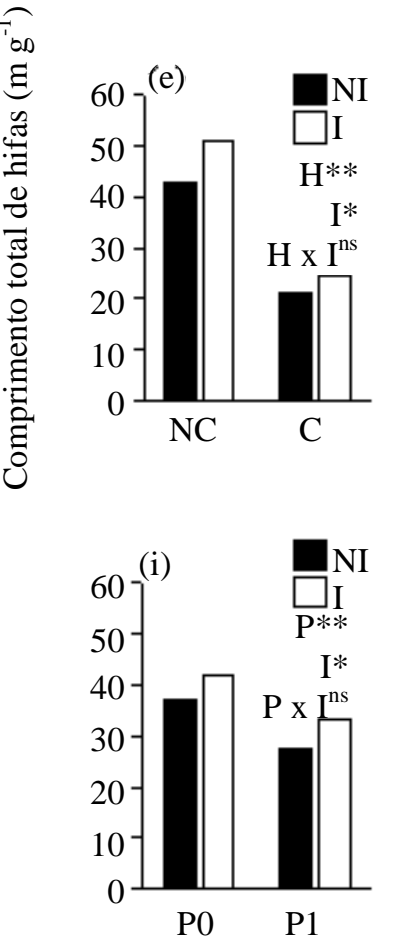

Soja

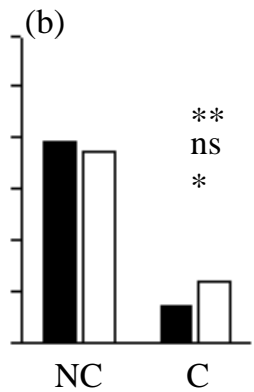

Latossolo Vermelho distroférrico

Braquiária

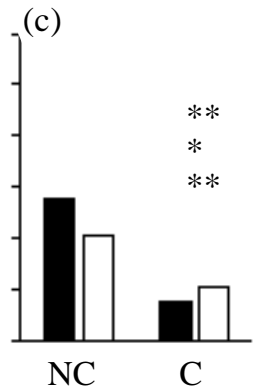

Histórico de uso
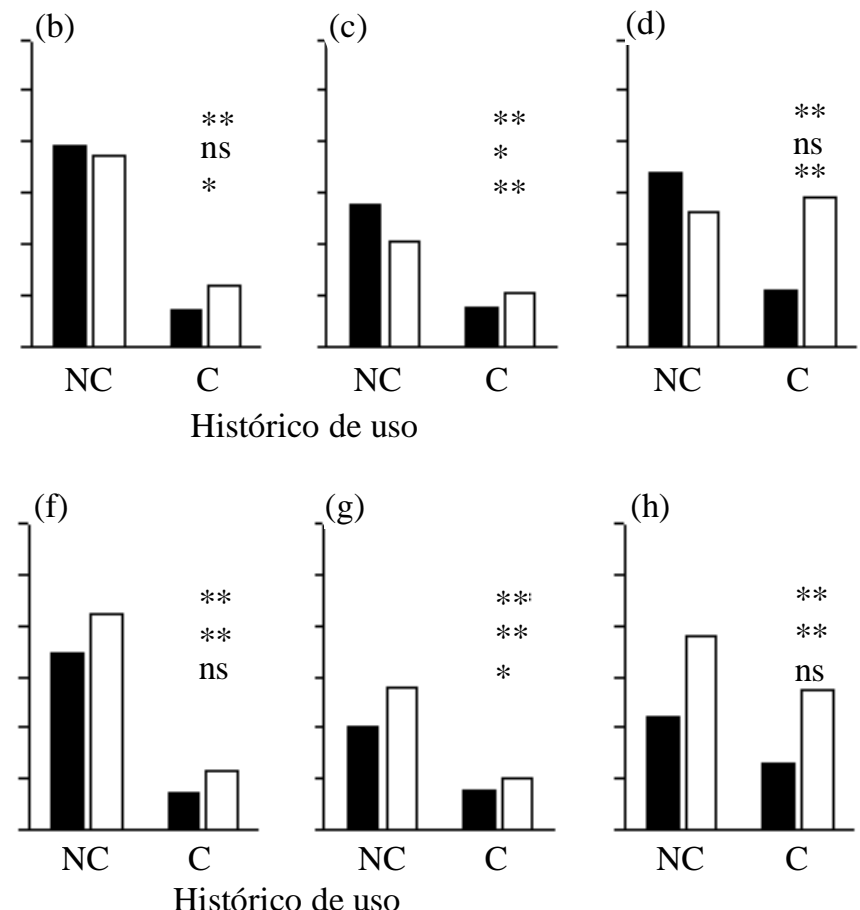
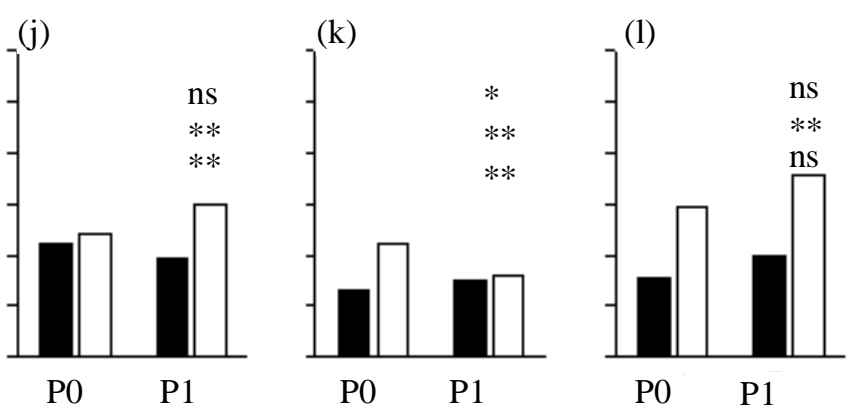

Níveis de fósforo

Figura 4. Efeito do histórico de uso, adubação fosfatada e inoculação sobre o comprimento total de hifas em agregados $>2 \mathrm{~mm}$ de um Latossolo Vermelho distrófico e Latossolo Vermelho distroférrico plantados com braquiária e soja (P: doses de fósforo; $\mathrm{H}$ : histórico de uso (NC: não-cultivado e C: cultivado); NI: não-inoculado; I: inoculado). ${ }^{\text {ns }}$ Não-significativo. * e **Significativo a $5 \%$ e a $1 \%$ de probabilidade, respectivamente.

são inicialmente reduzidos (P0), em comparação com o solo cultivado (Tabela 1). Efeito de interação $(\mathrm{P}<0,05)$ é também verificado entre adubação fosfatada e inoculação (Figura 3i); a maior dose de P no solo sem inoculação proporcionou maior produção de MSR. No geral, o efeito da micorrização sobre 
as plantas é reduzido quando se eleva o nível de $\mathrm{P}$ no solo; isto, devido a menor dependência da absorção via hifa (micotrofia) (Saggin-Júnior et al., 1994). No entanto, como plantas bem supridas em $\mathrm{P}$ não são imunes à colonização micorrízica (CM), esta, mesmo que numa baixa taxa nas raízes, pode constituir um dreno significativo de fotossintatos, e contribuir, assim, para a redução do crescimento (Peng et al., 1993), como sugere a taxa de CM de 9\% nesse tratamento (Tabela 2) ao reduzir a produção de MSR. No LVd com soja, verifica-se interação $(\mathrm{P}<0,01)$ entre o histórico de uso e a adubação fosfatada (Figura 3b), conforme também verificado em braquiária. Na soja, é verificado, também, efeito individual da inoculação $(\mathrm{P}<0,05)$ sobre a produção de MSR (Figura 3 (f, j)), o que mostra a maior dependência micorrízica dessa planta (Fernandes et al., 1987). No LVd foi também observado que, independentemente da cultura, maior produção de MSR ocorre no solo cultivado (Figura 3 (a, b, e, f)) devido ao maior teor de P nesse solo, resultante de adubações anteriores (Tabela 1), fato que também explica a falta de resposta da braquiária e soja à adição da maior dose de P nesse solo.

No LVdf com braquiária, é verificado apenas efeito individual do histórico de uso sobre essa variável, com maior produção de MSR no solo cultivado (Figura $3(\mathrm{c}, \mathrm{g})$ ), provavelmente em decorrência da maior disponibilidade de nutrientes às plantas nesse solo (Tabela 1). Por outro lado, a falta de resposta da braquiária à fosfatagem e à inoculação deve-se ao elevado teor inicial de P nesse solo (Tabela 1), suficiente para suprir as necessidades da braquiária, mes-

Tabela 2. Colonização micorrízica (\%) em braquiária e soja submetidas a inoculação de Glomus etunicatum em amostras de Latossolo Vermelho distrófico (LVd) e Latossolo Vermelho distroférrico (LVdf), previamente cultivados e sem cultivo (após o 2 o corte das plantas).

\begin{tabular}{cccccc}
\hline \multirow{2}{*}{$\begin{array}{c}\text { Dose de } \\
\text { fósforo }\end{array}$} & \multicolumn{2}{c}{ LVd } & & \multicolumn{2}{c}{ LVdf } \\
\cline { 2 - 4 } \cline { 5 - 6 } & Braquiária & Soja & & Braquiária & Soja \\
\hline & \multicolumn{4}{c}{ Não-cultivado } \\
P0 & 53 & 3 & 50 & 36 \\
P1 & 9 & 33 & 12 & 54 \\
\hline & \multicolumn{4}{c}{ Cultivado } \\
P0 & 41 & 16 & 30 & 29 \\
P1 & 0 & 12 & 0 & 28 \\
\hline
\end{tabular}

mo na dose mais baixa. Na soja, além do efeito individual do histórico, é observada interação $(\mathrm{P}<0,01)$ entre a adubação fosfatada e a inoculação (Figura 31). A inoculação aumenta a produção de MSR na menor dose de fósforo.

Na Tabela 2 são apresentadas as médias de CM, em razão dos tratamentos para braquiária e soja nos solos estudados. No LVd com braquiária, verifica-se que a CM é limitada pela maior dose de $\mathrm{P}$, principalmente no solo cultivado, devido à maior disponibilidade do $\mathrm{P}$, resultante de adubações anteriores (Tabela 1). Na soja, observa-se, no solo cultivado, o mesmo comportamento verificado na braquiária, embora de forma menos pronunciada. No solo não-cultivado, a maior dose de $\mathrm{P}$, ao contrário do observado na braquiária, contribui para aumentar a $\mathrm{CM}$. A braquiária apresenta maior porcentagem de $\mathrm{CM}$ que a soja, na menor dose de $\mathrm{P}$, e esse comportamento é revertido quando a maior dose é adicionada ao solo (Tabela 2). Comportamentos semelhantes foram observados por Fernandes et al. (1987) em plantas de milho e soja.

A diferenciação do efeito do P sobre a CM na braquiária e soja, principalmente no solo não-cultivado, deve-se provavelmente à natureza contrastante do sistema radicular dessas plantas, que, no caso da soja, é menos eficiente na captação de nutrientes do solo, especialmente do fósforo. Neste caso, é provável que o P talvez esteja num nível que limite o desenvolvimento da soja, limitando também o crescimento do fungo (Sainz \& Arines, 1988), tornando a maior dose um estimulante para $\mathrm{CM}$ nas raízes dessa planta.

No LVdf com braquiária e soja, observa-se comportamento semelhante ao do solo anterior, embora, na soja, a CM no solo cultivado ocorra de forma indiferente às doses de fósforo.

Mesmo nos tratamentos sem inoculação (porcentagem de CM zero), observam-se valores consideráveis de $\mathrm{CTH}$, muitas vezes com valores similares ao solo inoculado (Figura 4). Tal fato se deve ao método de quantificação do micélio extrarradicular usado neste trabalho, que não diferencia hifas de FMAs dos não-micorrízicos (saprofíticos), que também se encontram na massa do solo.

Nesse sentido, são verificados, no LVd com braquiária, efeitos individuais do histórico de uso 
$(\mathrm{P}<0,01)$, da adubação fosfatada $(\mathrm{P}<0,01)$ e da inoculação $(\mathrm{P}<0,05)$ com valores mais elevados no solo não-cultivado, com menor dose de $\mathrm{P}$ e inoculação (Figura $4(\mathrm{a}, \mathrm{e})$ ). O maior CTH no solo não-cultivado e com inoculação (Figura 4e) explica o maior DMG nesse solo (Figura 1e), conforme também observado por Miller \& Jastrow (1990). Esse efeito da inoculação na braquiária ocorre na menor dose de P (Figura 4 (a, i)). Na soja, é observada interação $(\mathrm{P}<0,05)$ entre histórico de uso e adubação fosfatada, e adubação fosfatada e inoculação $(\mathrm{P}<0,01)$, conforme verificado na Figura $4(\mathrm{~b}, \mathrm{j})$. No solo cultivado, o aumento do CTH (Figura 4b) na maior dose de P (Figura 4j) explica o aumento do DMG verificado na Figura $1 b$. No LVd, observa-se que, independentemente da cultura, maior CTH ocorre no solo não-cultivado, o que, certamente, contribui para ocorrência de agregados mais estáveis nesse solo (Miller \& Jastrow, 1990). Também foram encontradas, por Tisdall (1994), relações estreitas entre cultivo, CTH e proporção de agregados estáveis.

No LVdf com braquiária, são observadas interações entre o histórico de uso e a adubação fosfatada $(\mathrm{P}<0,01)$, histórico de uso e inoculação $(\mathrm{P}<0,05)$, e adubação fosfatada e inoculação $(\mathrm{P}<0,01)$, conforme verificado na Figura 4 (c, g, k). Na Figura 4k, observa-se que a inoculação só aumenta o CTH na menor dose de P, principalmente no solo não-cultivado (Figura 4 (c, g)), fato que explica o aumento verificado no DMG (Figura 1g). Na soja, é observado, além da interação entre histórico de uso e adubação fosfatada (Figura 4d), efeito individual da inoculação (Figura $4(\mathrm{~h}, 1)$ ). No solo cultivado (Figura 4d), a maior dose de $\mathrm{P}$ propiciou aumento no CTH, provavelmente devido ao menor nível de $\mathrm{P}$ nesse solo, que pode estar limitando o desenvolvimento do fungo quando em associação com a cultura da soja. De acordo com Sainz \& Arines (1988), adições de pequenas doses de $\mathrm{P}$ em solos com menor disponibilidade desse nutriente podem aumentar a porcentagem de CM e produção de micélio externo.

\section{Conclusões}

1. O cultivo reduz a estabilidade dos agregados do solo, o índice de floculação das partículas de argila, e o crescimento de hifas no solo.

2. A estabilidade dos agregados, produção de matéria seca de raiz, colonização micorrízica e comprimento total de hifas, beneficiam-se da inoculação do Glomus etunicatum e da adubação fosfatada e esses benefícios são diferenciados entre o histórico de uso, doses de $\mathrm{P}$, e espécies de plantas.

\section{Referências}

ANDRADE, G.; MIHARA, K. L.; LINDERMAN, R. G.; BETHLENFALVAY, G. J. Soil aggregation status and rhizobacteria in the mycorrhizosphere. Plant and Soil, Dordrecht, v. 202, n. 1, p. 89-96, May 1998.

BUTTIERRES, M. F. M. Efeito do calcário e fosfato de potássio no ponto de carga zero ( $\mathrm{PCZ}$ ) e grau de floculação em três solos do Rio Grande do Sul. Santa Maria: UFSM, 1980. 59 p. Dissertação de Mestrado.

CAMPOS, B. C.; REINERT, D. J.; NICOLODI, R.; RUEDELL, J.; PETRELE, C. Estabilidade estrutural de um Latossolo Vermelho-Escuro distrófico após sete anos de rotação de culturas e sistemas de manejo do solo. Revista Brasileira de Ciência do Solo, Campinas, v. 19, n. 1, p. 121-126, jan./abr. 1995.

CARPENEDO, V.; MIELNICZUK, J. Estado de agregação e qualidade de agregados de Latossolos Roxos, submetidos a diferentes sistemas de manejo. Revista Brasileira de Ciência do Solo, Campinas, v. 14, n. 1, p. 99-105, jan./abr. 1990.

DORIOZ, J. M.; ROBERT, M.; CHENU, C. The role of roots, fungi and bacteria on clay particle organization. An experimental approach. Geoderma, Amsterdam, v. 56, n. 1/4, p. 179-194, Mar. 1993.

EMBRAPA. Centro Nacional de Pesquisa de Solo (Rio de Janeiro, RJ). Manual de métodos de análise de solo. Rio de Janeiro, 1997. 212 p.

FERNANDES, A. B.; SIQUEIRA, J. O.; MENEZES, M. A. L.; GUEDES, G. A. A. Efeito diferenciado do fósforo sobre o estabelecimento e efetividade da simbiose endomicorrízica em milho e soja. Revista Brasileira de Ciência do Solo, Campinas, v. 11, n. 2, p. 101-108, maio/ ago. 1987.

FERREIRA, M. M.; FERNANDES, B.; CURI, N. Influência da mineralogia da fração argila nas propriedades físicas de latossolos da região sudeste do Brasil. Revista Brasileira de Ciência do Solo, Campinas, v. 23, n. 3, p. 515524, jul./set. 1999

GERDERMANN, J. N.; NICOLSON, T. H. Spores of mycorrhizal Endogone species extracted from soil by wet 
sieving and decanting. Transactions of the British Mycological Society, London, v. 46, p. 235-244, 1963.

GIOVANNETTI, M.; MOSSE, B. An evaluation of techniques for measuring vesicular-arbuscular mycorrhizal infection in roots. New Phytologist, London, v. 84, n. 3, p. 484-500, Mar. 1980

KÄMPF, N.; SCHWERTMANN, U. The $5 \mathrm{M}-\mathrm{NaOH}$ concentration treatment for iron oxides in soils. Clays and Clay Minerals, Lawrence, v. 30, n. 6, p. 401-408, 1982

KEMPER, W. D.; ROSENAU, R. C. Aggregate stability and size distribution. In: KLUTE, A. (Ed.). Methods of soil analysis. 2. ed. Madison: American Society of Agronomy, 1986. v. 1, p. 425-442.

LIMA, J. M.; ANDERSON, S. J.; CURI, N. Phosphateinduced clay dispersion as related to aggregate size and composition in Hapludoxs. Soil Science Society of America Journal, Madison, v. 64, n. 3, p. 892-897, May/ June 2000 .

MEHRA, O. P.; JACKSON, M. L. Iron oxide removal from soils and clays by dithionite-citrate system buffered with sodium bicarbonate. In: NATIONAL CONFERENCE ON CLAY AND CLAY MINERALS, 7., 1958, Washington. Proceedings... Washington: Pergamon, 1960. p. 317 327.

MELLONI, R.; CARDOSO, E. J. B. N. Quantificação de micélio extrarradicular de fungos micorrízicos arbusculares em plantas cítricas e endófitos. I. Método empregado Revista Brasileira de Ciência do Solo, Viçosa, v. 23 n. 1, p. 53-58, jan./mar. 1999

MILLER, R. M.; JASTROW, J. D. Hierarchy of root and mycorrhizal fungal interactions with soil aggregation. Soil Biology \& Biochemistry, Oxford, v. 22, n. 5, p. 579-584, 1990.

NEWMAN, E. I. A method for estimating the total length of root in a sample. Journal of Applied Ecology, Oxford, v. 3, p. 139-145, 1966.

OADES, J. M.; WATERS, A. G. Aggregate hierarchy in soils. Australian Journal of Soil Research, Collingwood, v. 29 , p. $815-828,1991$
PENG, S.; EISSENSTAT, D. M.; GRAHAM, J. H.; WILLIAMS, K.; HODGE, N. C. Growth depression in mycorrhizal citrus at high-phosphorus supply. Analysis of carbon costs. Plant Physiology, Rockville, v. 101, n. 3, p. 1063-1071, Mar. 1993.

ROSA JÚNIOR, E. J. Efeito de sistemas de manejo e tempo de uso sobre características físicas e químicas de dois solos no Município de Ponta Porã, MS. Viçosa, MG: UFV, 1984. 89 p. Dissertação de Mestrado.

SAGGIN-JÚNIOR， O. J.; SIQUEIRA， J. O.; GUIMARÃES, P. T. G.; OLIVEIRA, E. Interação fungos micorrízicos versus superfosfato e seus efeitos no crescimento e teores de nutrientes do cafeeiro em solo não fumigado. Revista Brasileira de Ciência do Solo, Campinas, v. 18, n. 1, p. 27-36, jan./abr. 1994.

SAINZ, M. J.; ARINES, J. Effect of indigenous and introduced vesicular-arbuscular mycorrizal fungi on growth and phosphorus uptake of Trifolium pratense and on inorganic $\mathrm{P}$ fractions in a Cambisol. Biology and Fertility of Soils, Berlin, v. 6, p. 55-60, 1988

SILVA, I. F.; MIELNICZUK, J. Ação do sistema radicular de plantas na formação e estabilização de agregados do solo. Revista Brasileira de Ciência do Solo, Campinas, v. 21, n. 3, p. 113-117, set./dez. 1997.

SILVA, R. B.; LIMA, J. M.; DIAS JÚNIOR, M. S. Efeito da adsorção de fosfato em parâmetros físicos e na compressibilidade de solos tropicais. Revista Brasileira de Ciência do Solo, Viçosa, v. 23, n. 2, p. 219-226, abr./ jun. 1999.

TISDALL, J. M. Possible role of soil microorganisms in aggregation in soils. Plant and Soil, Dordrecht, v. 159, n. 1, p. 115-121, Feb. 1994

TISDALL, J. M.; OADES, J. M. Organic matter and water-stable aggregates in soils. Journal of Soil Science, Oxford, v. 33, n. 1, p. 141-163, Mar. 1982

TISDALL, J. M.; OADES, J. M. Stabilization of soil aggregates by the root systems of ryegrass. Australian Journal of Soil Research, Collingwood, v. 17, p. 429441, 1979.

VETTORI, L. Métodos de análise de solo. Rio de Janeiro: Ministério da Agricultura, 1969. 24 p. (Boletim Técni$\operatorname{co}, 7)$ 